\title{
Effect of Growth Regulators on In Vitro Morphogenic Response of Boscia senegalensis (Pers.) Lam. Poir. Using Mature Zygotic Embryos Explants
}

\author{
Hussien H. Daffalla, ${ }^{1}$ Eltayb Abdellatef, ${ }^{1}$ Elsadig A. Elhadi, ${ }^{2}$ and Mutasim M. Khalafalla ${ }^{1}$ \\ ${ }^{1}$ Commission for Biotechnology and Genetic Engineering, National Centre for Research, P.O. Box: 2404, Khartoum, Sudan \\ ${ }^{2}$ Desertification Research Institute, National Centre for Research, P.O. Box 2404, Khartoum 11111, Sudan \\ Correspondence should be addressed to Hussien H. Daffalla, hdaffalla@yahoo.com
}

Received 13 September 2010; Revised 11 November 2010; Accepted 28 January 2011

Academic Editor: Maxim Golovkin

Copyright (C) 2011 Hussien H. Daffalla et al. This is an open access article distributed under the Creative Commons Attribution License, which permits unrestricted use, distribution, and reproduction in any medium, provided the original work is properly cited.

\begin{abstract}
The percent study describes the in vitro responses of mature zygotic embryos of Boscia senegalensis to different concentrations (0.0-5.0 mg/L) of 6-benzyladnine (BA), Thidiazuron (TDZ), $\alpha$-Naphthalene acetic acid (NAA), and 2, 4-Dichlorophenoxyacetic acid (2, 4-D) supplemented on Murashige and Skoog medium (MS). The plant growth regulators (PGRs) were considerably affected the morphogenetic responses. BA produced adventitious shoots through two ways: direct organogenesis and auxiliary shoot formation. Both 2, 4-D and TDZ tend to produce callus, whereas NAA improve the development of embryos to seedlings. Maximum number of shoots/explant (14.8 \pm 0.6$)$ was obtained on MS medium supplemented with 3.0 mg/L BA. 67.0\% of excised shoots were rooted either on $1 / 2 \mathrm{MS}$ medium augmented with or without $0.25 \mathrm{mg} / \mathrm{L}$ IBA. The highest number of roots $(1.2 \pm$ $0.4)$ and root length $(0.5 \pm 0.2 \mathrm{~cm})$ was produced on $0.25 \mathrm{mg} / \mathrm{L}$ IBA-containing medium. Regenerated plants were successfully acclimatized and transferred to the green house with $70 \%$ survival rate. All the plants appeared morphologically uniform with normal growth pattern. A rapid (30 days), efficient and without subculturing protocol for in vitro regeneration of $B$. senegalensis was developed.
\end{abstract}

\section{Introduction}

Boscia senegalensis (Pers.) Lam. ex Poir. (Capparidaceae) is an evergreen drought tolerant shrub widespread across the Sahel and Sahara savannas from Mauritania across central Africa to Sudan [1]. This area of semiarid and arid region with extremely high temperatures and low rainfall provides the highly hottest and driest conditions ever faced by higher plant life $[2,3]$. B. senegalensis is very well adapted to this unusual degree of drought $[3,4]$. It tolerates temperatures as high as $45^{\circ} \mathrm{C}$ and survives with $100 \mathrm{~mm}$ annual rainfall, but $250 \mathrm{~mm}$ is sufficient for its vigorous growth [2]. Under such desiccating conditions, this wild species make life more bearable for millions of destitute people who struggle to survive. It produces enough different products to sustain human and animal life almost by itself. The significant role of $B$. senegalensis in the African rural agroeconomy and daily life has been illustrated by several reports $[1,4,5]$. During the 1984-85 famine in Kordofan and Darfur, western Sudan, people relied on the so-called famine foods, mukheit $[3,6]$. In fact, seed flour commonly replaces sorghum, millet, or lentils as staple food [2]. The property of B. senegalensis to protect cereals against several stored grain insect species and pathogens has been reported $[7,8]$. Those fresh leaves were traditionally added to stored grains in order to limit insect infestation and damages $[1,7]$. The presence of methylisothiocyanate and methylcyanide enzymatically liberated from the methylglucosinolate, in addition to glucanase justified their uses as insecticide and antifungal $[1,7]$.

Conventional propagation of this plant is through seeds, but it is restricted due to poor growth rate of seed and low germination percentage [9]. The seed is recalcitrant and nondormant thus rapidly lose viability (1-2 seasons) due to embryo eradication when water contents decreased below 
20-30\% subsequent to its harsh hostile environment [10, 11]. On the other hand, fruits after ripping frequently attacked by fungus and then seed borers due to its high sugar content. Moreover, seed is endozoochorous and depend on birds to remove germination inhibitor in fruit pulp when seeds passage through digestive tract and defecate in a favorable site $[12,13]$. Thereafter, new naturally established seedlings are commonly found under Acacia trees. This makes the plant are reliant on large tree species, and it may be threatened if they are removed [13]. The slow growth rate of this arid land species is likely attributable to extensive investment in establishing and maintaining a deep taproot system, prior to aboveground growth $[12,13]$. In vitro tissue culture technologies would not only overcome those limitations but also offer fascinating methods for large-scale production of plants in shorter time irrespective of seasonal constraints. Thus, payable to the nature of $B$. senegalensis seeds, embryo culture can facilitate obtaining plants in a short time. This represents a simple way of in vitro regeneration without subculture and with addition of only a few numbers of phytohormones. The objective of this study is to investigate the response of $B$. senegalensis tissues in vitro to various growth regulators at various concentrations to identify optimum conditions for adventitious regeneration of shoots from embryo.

\section{Materials and Methods}

2.1. Plant Materials. Fully grown green fruits of B. senegalensis were collected at Al-Rawakeeb Research Station, West Omdurman, Sudan, during February 2009. The target plant material was the mature green embryo; however, each seed may contain 1-4 embryos.

2.2. Surface Disinfection and Sterilization. Fruits were thoroughly washed in running tap water to remove any soil attached to fruits surface. Aseptically, fruits were surface sterilized in $70 \%(\mathrm{v} / \mathrm{v})$ ethanol for 3 minutes, followed by $15 \%$ $(\mathrm{v} / \mathrm{v})$ Clorox commercial bleach solution $(4.5 \%-5 \%(\mathrm{v} / \mathrm{v})$ Sodium Hypochlorite) for 15 minutes, then rinsed 3 times with autoclaved distilled water.

2.3. Explant Preparation. The sterilized fruits were kept in autoclaved distilled water to facilitate zygotic embryo excision. Embryos were aseptically excised from the sterilized fruits by tearing out the fleshy pulp, endosperms, and the seed peel using sharp surgical blades and tweezers. The excised embryo was round in shape with thick cotyledons enveloping the embryonic axis. After a careful excision, the embryos were immersed and rinsed five times in autoclaved distilled water for removal of the growth inhibitor and hastened the germination process.

2.4. Media and Culture Conditions. Murashige and Skoog [14] (MS) basal medium was prepared and used in all cultures. The medium was adjusted to the desired $\mathrm{pH} 5.8$ using $\mathrm{HCl}$ or $\mathrm{NaOH}$. A gelling of $7 \mathrm{~g} / \mathrm{L}(\mathrm{w} / \mathrm{v})$ agar was added, heated until the solution was clear, and then dispensed into the culture vessels before autoclaving. The medium was sterilized in autoclave at $15 \mathrm{psi}$ at $121^{\circ} \mathrm{C}$ for 15 minutes. The culture was incubated at constant temperature of $25 \pm$ $2^{\circ} \mathrm{C}$, under cool fluorescent light of about 5,000 lx, and a photoperiod of 16 light and $8 \mathrm{~h}$ dark.

2.5. Plant Growth Regulators (PGRs). Semisolid MS media supplemented with different plant growth regulators (PGRs) were used as multiplication medium. The effects of cytokinins BA, an adenine-type cytokinin, and TDZ, a substituted phenylurea cytokinin, and auxins 2, 4-D and $\alpha$-naphthalene acetic acid (NAA) were investigated separately. The PGRs were supplemented alone in an attempt to evaluate and stimulate clonal shoot multiplication and shoot development. Furthermore, PGRs used were applied at wide range of concentrations $(0.0,1,2,3$, and $5 \mathrm{mg} / \mathrm{L})$. For root induction, 1/2-strength MS medium supplemented with 3indole butyric acid (IBA) at $0.0,0.25,0.5$, or $1 \mathrm{mg} / \mathrm{L}$, was used.

2.6. Embryo Culture. Embryos excised having the intact embryonic axis (shoot meristem + hypocotyl) with cotyledons were used as explant and was implanted directly on multiplication media. One embryo explants were placed horizontally on the surface of the medium in ten tubes $(20 \times$ $3 \mathrm{~cm}, 15 \mathrm{~mL}$ ) for every concentration. The cultures were incubated under darkness at $28 \pm 2^{\circ} \mathrm{C}$ for 7 days. Two experiments were conducted separately.

2.7. Shoots Multiplication. After 4 weeks of culture, every embryo explants that produced shoot buds was transferred to $(9 \times 2 \mathrm{~cm})$ bottles containing $30 \mathrm{~mL}$ of its same fresh multiplication medium. The subculturing was done for further growth, shoot elongation, and multiplication. Well-developed and elongated shoots $(1-1.5 \mathrm{~cm})$ were harvested from the multiplication clusters and counted for each treatment. The maximum number of shoots and shoots length were recorded after four weeks of culture.

2.8. In Vitro Rooting. To induce roots, shoots $1-1.5 \mathrm{~cm}$ were separated from multiple shoots and then cultured in rooting media as described above. Data were recorded in terms of percentage of rooting, number, and length of roots/shoots after four weeks of culture.

2.9. Acclimatization of Plantlets. Rooted plantlets of about $5 \mathrm{~cm}$ in length $(4 \mathrm{~cm}$ long shoot, $1 \mathrm{~cm}$ long root), were washed in running tap water, and transplanted into autoclaved mixture of silt: sand soil $(2: 1, \mathrm{v} / \mathrm{v})$ filled plastic pots $(5 \times 10 \mathrm{~cm})$. The pots were maintained at $30^{\circ} \mathrm{C}$ in a polyhouse with relative humidity $50-60 \%$. The regenerated plantlets acclimatized for four to eight weeks and were successfully transferred to the soil under greenhouse conditions.

2.10. Statistical Analysis. The experiment was conducted as factorial using a completely randomized design with 10 replications. MS medium was supplemented with four growth regulators (4 factors) supplied at four concentrations 
TABle 1: Effect of different PGRs benzyl adenine (BA), thidiazuron (TDZ), $\alpha$-naphthalene acetic acid (NAA), and 2, 4-dichlorophenoxy acetic acid (2, 4-D) concentrations on in vitro morphogenesis on B. senegalensis embryo explants after 4 weeks of culture.

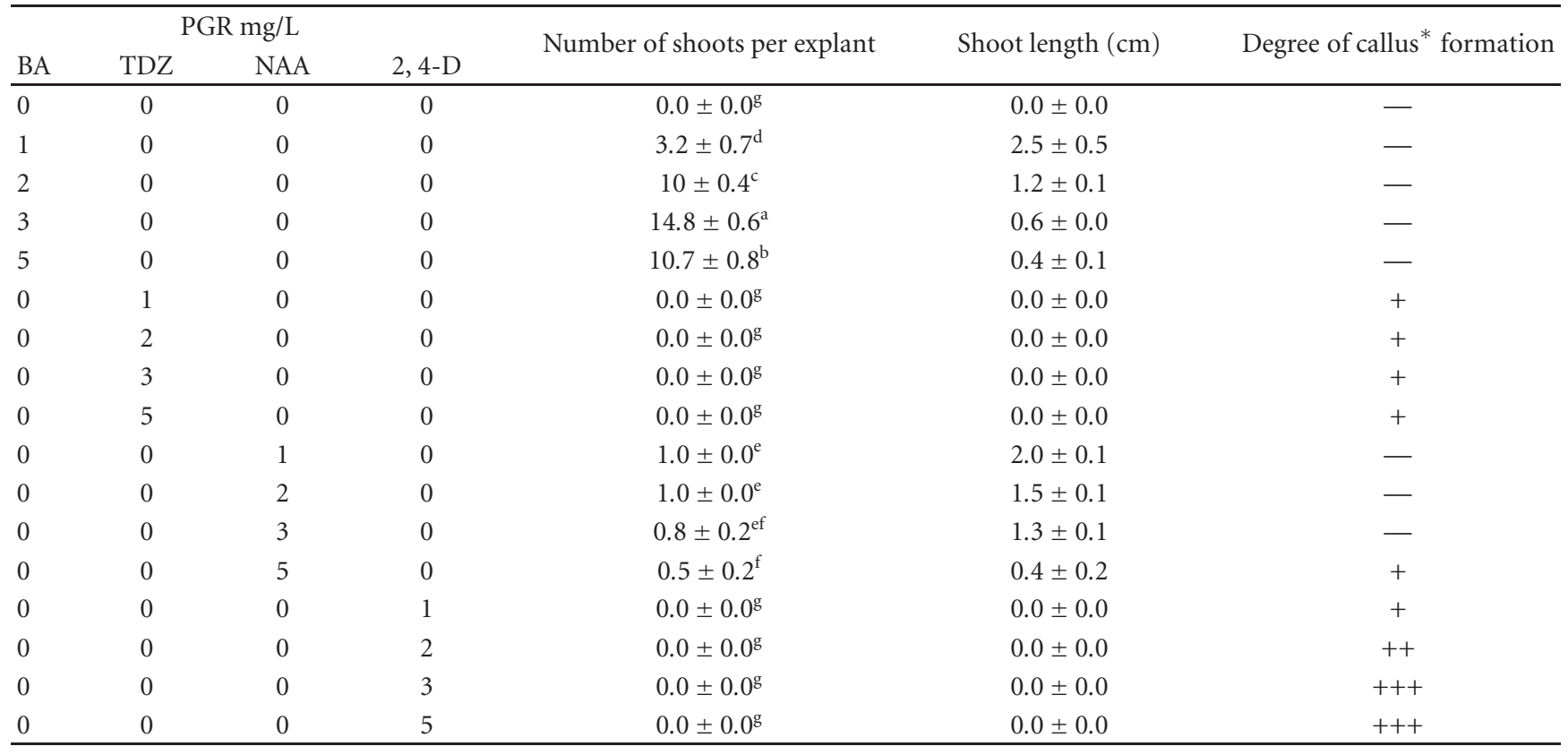

Each value represents the mean + standard error of at least ten replicates. * Degree of callus formation was represented as: —; no callus formed, + ; slight callus, ++ ; moderate callus; +++; massive callus formation.

(levels). Data on number of shoots per explant shoot, length, and callusing degree were recorded. The parameters recorded for rooting were number of roots per shoot, root, length, and rooting percentage.

\section{Results and Discussion}

Determination of the most optimal types and concentrations of plant growth regulators as medium constituents is one of the most important aspects of successful micropropagation, among other in vitro factors [15]. The initial explants were intact mature zygotic embryos $(10 \times 5 \mathrm{~mm})$ of $B$. senegalensis cultured on different media composition as given in Table 1 . The embryo explants inoculated responded gradually to culture $(96 \%)$, and no contamination was recorded. In some experiment, there were several embryos that did not show any response, which may be due to incomplete removal of growth inhibiters, turned to white, and died. Under natural conditions, the seed dispersal is through birds, appears to be vitally important to this species, as bird digest the flesh of the fruit surrounding the seed thus removing germination inhibitor, and favours the imbibitions phenomena.

3.1. The Effects of PGRs on Embryo Response. After a week of culture, the embryos spread slightly from rounded form to nearly "Y" shape with cotyledons and hypocotyl but without presence of plumules. After another week in culture, a greenish swelling of the cotyledons and hypocotyl was observed. Later, within three weeks of culturing, they continued to swell without emergence of plumules. After four weeks, all cultures were responding in different ways depending on the different PGRs, as follows.

On the control treatment (no growth regulators), embryos were fully spread into " $\mathrm{Y}$ " shape developing seedling with two cotyledons and hypocotyl-root axis, but the epicotyls appear only at the seventh week of inoculation (Figure 1(a)). However, the radicle elongated to one unbranched long taproot.

Although the NAA was stimulatory to root formation and embryo maturation, it appeared to suppress shoot growth and multiplication. Each embryo develops to a seedling with all parts but does not germinate to more than that (Figure 1(b)). The presence of the auxin in concentrations $1-3 \mathrm{mg} / \mathrm{L}$ improved root elongation and produced $1-3$ thick single taproots. Higher concentration of NAA $(5.0 \mathrm{mg} / \mathrm{L})$ was not beneficial and also resulted in callus formation at the base of explant.

BA treatments induced complete seedlings development with well-formed cotyledons, hypocotyls, and principal shoot. The radicles did not elongate to tap root (Figure 1(c)). Bud induction was visible at the apical portion and cotyledonary node area. Many organogenic buds were induced per embryo explant at hypocotyle-root axis and latter developed to microshoots. Based on the fact that lateral buds can be inhibited by apical auxin application [15], and released by cytokinins [16], embryo explant produces one shoot when NAA added and multiple shoots with presence of BA.

The auxin 2, 4-D and the cytokinin TDZ appear to induce calluses but in different forms. That, as generally known about 2, 4-D, when used embryos formed a pale yellow-colored friable callus (Figure 1(d)), whereas, when embryo explants cultured on TDZ-supplemented medium, 


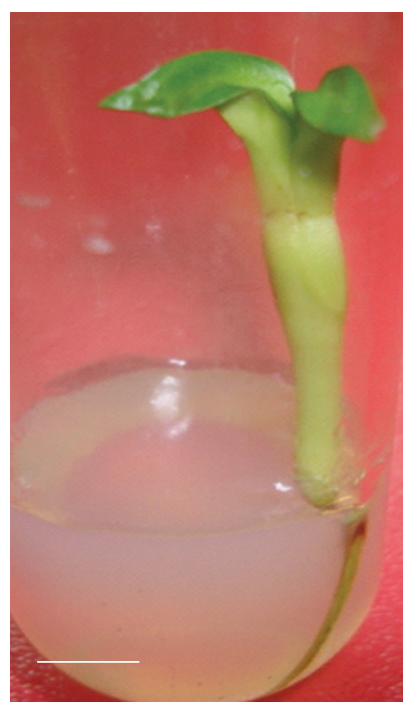

(a)

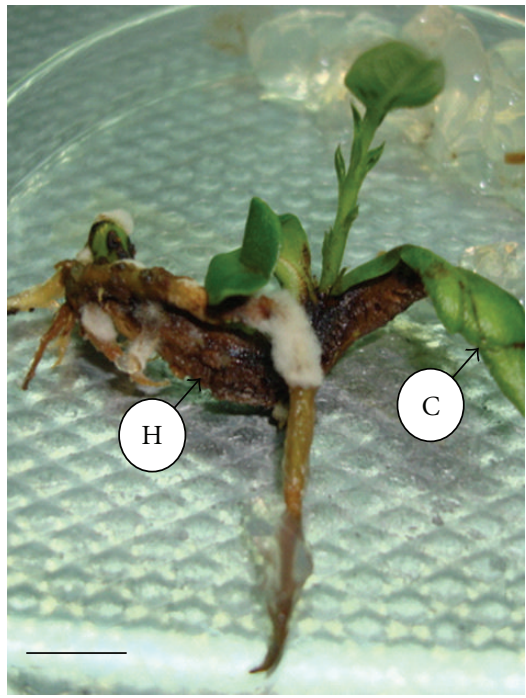

(b)

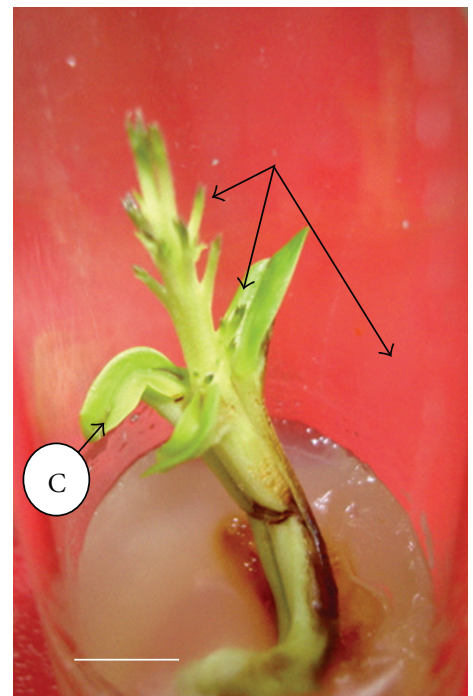

(c)

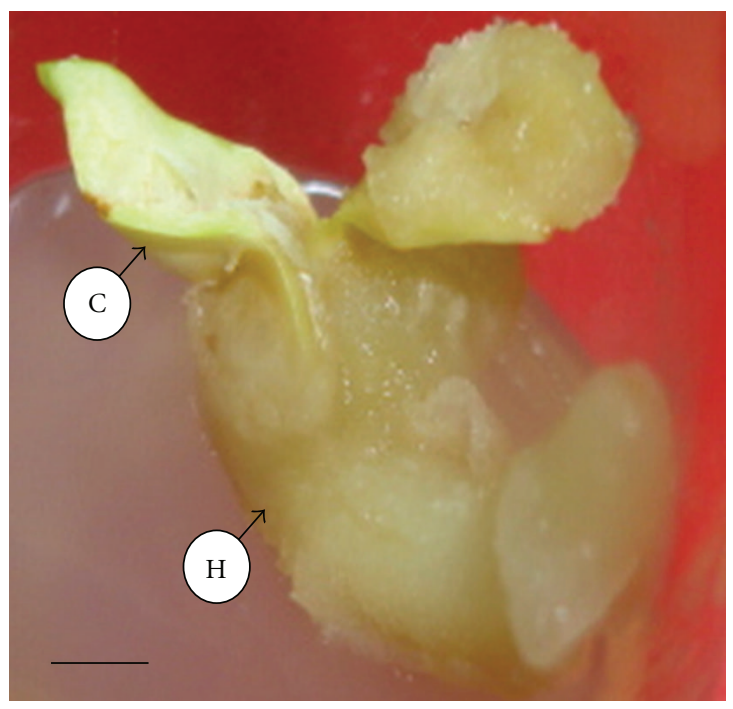

(d)

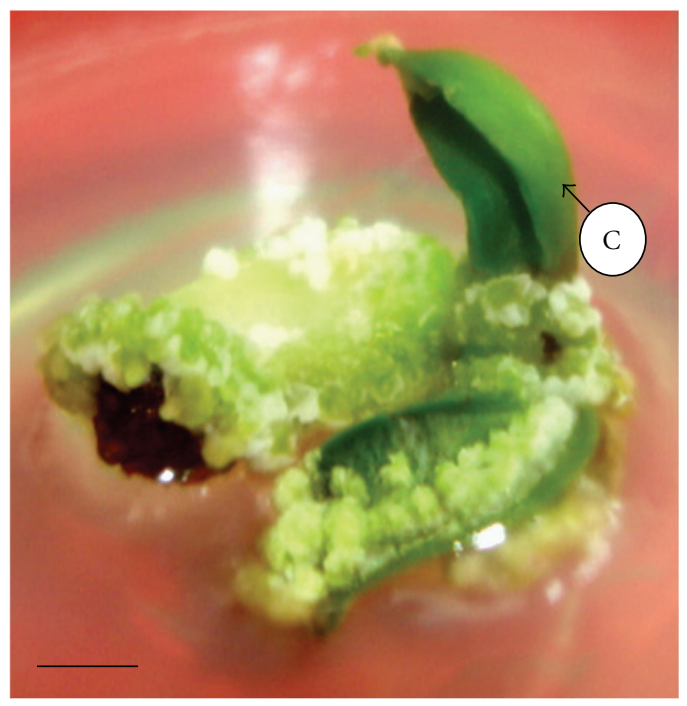

(e)

FIGURE 1: Effect of different PGRs on in vitro morphogenesis on mature zygotic embryo of B. senegalensis after 4 weeks of culture, where C: cotyledon, H: hypocotyl, R: radicle. (a) Embryo germination without presence of epicotyls (control), Bar $=1.0 \mathrm{~cm}$. (b) Shoot growth and root formation (NAA), Bar $=0.6 \mathrm{~cm}$. (c) Embryo develops to seedling with presence of adventitious (arrows), Bar $=1.0 \mathrm{~cm}$. (d) Soft callus (2, 4-D), Bar $=0.5 \mathrm{~cm}$. (e) Nodular callus $(\mathrm{TDZ})$, Bar $=0.65 \mathrm{~cm}$.

TABLE 2: Effect of different Indole-3-butyric acid (IBA) concentrations on in vitro rooting of B. senegalensis shoots after 4 weeks of culture.

\begin{tabular}{lccc}
\hline IBA $(\mathrm{mg} / \mathrm{L})$ & Number of roots per rooted shoot & Root length $(\mathrm{cm})$ & Rooting percentage $(\%)$ \\
\hline 0.0 & $1.0 \pm 0.3$ & $0.4 \pm 0.1$ & 67 \\
0.25 & $1.2 \pm 0.4$ & $0.5 \pm 0.2$ & 67 \\
0.5 & $0.3 \pm 0.2$ & $0.1 \pm 0.1$ & 33 \\
1.0 & $0.4 \pm 0.2$ & $0.3 \pm 0.1$ & 33 \\
\hline
\end{tabular}

Each value represents the mean + standard error of at least 10 replicates.

scattered protuberances were formed on their surfaces (Figure 1(e)). These protuberances became leaf primordialike structures, but they did not develop into shoots. With all 2, 4-D concentrations, whole embryo explants tissues turned to callus without organs development. Application of TDZ induces a range of responses in explant tissues; from callusing to somatic embryogenesis. This varies widely depending on its concentration, exposure time, cultured explant, and species [17]. The differential ability of cytokinins in induction of shoots could be attributed to factors such as stability, 
mobility, and the rate of conjugation and oxidation of the hormones [18]. Thus, the hormonal conditions appear to be a determining factor for the successful enhancement of adventitious bud formation and shoots proliferation. TDZ is less susceptible to the plant's degrading enzymes than are endogenous cytokinins, and is active at lower concentrations ( 1 to $10 \mu \mathrm{M}$ ) than the amino purine cytokinins [19]. This range with TDZ generally results in excessive callus formation and cessation of shoot growth. The growth of callus is supposed to inhibit axillary shoot proliferation in woody plant tissue culture. However, it is possible to inhibit callus growth with extremely high concentrations of TDZ $(1000 \mu \mathrm{M})$ [19].

On the other hand, the auxin NAA and the cytokinin BA promote shoot growth. This may be attributed to the complex interactions of original hormonal content of explants with that supplied. B. snegalensis is a drought-resistant plant with high antioxidant activities. These kinds of plants increase endogenous cytokinin to high levels to tolerate drought stress [20]. Therefore, the internal cytokinins act as antioxidant defense system and decrease damaging effects of drought [21]. That high level of endogenous cytokinin and its production are reported to increase in explants tissue with presence of NAA or BA in the medium [14]. In this sense, that uptake of NAA from the culture medium of $B$. senegalensis causes an increase in endogenous cytokinins and IAA levels, which appears to be involved in producing a seedling with one shoot (Table 1). Moreover, IAA is not very effective in the formation of callus, but it shows a very high performance with respect to adventitious organ formation and inhibition of auxiliary buds [22]. When BA is applied, it can increase content of endogenous cytokinins more than NAA did, by its uptake, increasing oxidase activity and degradation, and by promotion of cytokinin biosynthesis [23]. Therefore, more than one shoot formed through organogenic or auxiliary bud formation (Table 1).

BA seemed to be maintaining adequate contents of phytohormones essential for efficient organogenesis, proliferation, and shoot development and was not associated with callus induction. NAA produced only one shoot, while 2, 4-D and TDZ simultaneously induced callus formation and suppressed the direct shoot regeneration pathway. Rapid regeneration is a procedure with low incidence of undesirable somaclonal variation. A lot of minor genes and environmental factors affect regeneration through callus [24]. In contrast, direct regenerations are more stable, simple and needs less time to regenerate a large number of plants with low incidence of somaclonal variation and chromosomal abnormalities [25]. So, although there was ability to develop plant regeneration system through indirect multiple shoot differentiation from callus induced by 2, 4-D and TZD, it was ignored in this study.

3.2. Direct Multiple Shoots Induction and Multiplication. After 4 weeks of subculture, various numbers of adventitious shoots/explant sprouted on embryo explants. All the concentrations of BA facilitated shoot bud differentiation, but the concentrations were not all the same. BA $3.0 \mathrm{mg} / \mathrm{L}$ showed the maximum number of shoots produced (14.8 \pm 0.6 ) with shoot length $(0.6 \pm 0.0 \mathrm{~cm})$ (Table 1$)$, whereas BA at $1 \mathrm{mg} / \mathrm{L}$ produced the highest shoot length $(2.5 \pm 0.5 \mathrm{~cm})$ observed in the experiment of an average number of shoots $(3.2 \pm 0.7)$. However, with BA at $2 \mathrm{mg} / \mathrm{L}$, the highest number of shoots $(10 \pm 0.4)$ and shoot length $(1.2 \pm 0.1 \mathrm{~cm})$ were achieved. The shoots $(10.7 \pm 0.8)$ raised and developed on $5.0 \mathrm{mg} / \mathrm{L} \mathrm{BA}$, with length of $0.4 \pm 0.1 \mathrm{~cm}$, did not elongate further. The regeneration frequencies of shoots number and height declined with an increase in cytokinin concentration beyond the optimal level. Reduction in number of shoots in the concentrations higher than optimal level has also been reported for several woody plants [26]. The marked effect of BA on shoot formation compared to TDZ as observed in this study may attributed to its high stability in in vitro cultures that is in agreement with many authors who reported that BA has superior shoot induction ability over cytokinins [27]. $\mathrm{BA}$ is not easily broken down and therefore persists in the medium. It is also possible that the amount of BA that got conjugated in the medium was smaller than what happened to the other plant hormones. This would then have larger amount of BA existing in their free or ionized forms and were readily made available to plant tissues from the medium [28].

Adventitious shoots were inducing on cotyledonary node, whereas a higher frequency of organogenic tissue initiation was obtained on hypocotyl-root axis. The threshold concentrations of the growth regulators required for organogenetic induction and optimal response differed for different explant parts. Shoot organogenesis was observed at three distinct sites along the cotyledonary explant with the highest frequency noted along the basal segment of the cotyledon to the hypocotyl. In terms of sites of biosynthesis, high cytokinin levels have been reported to occur in roots, immature leaves, and apical buds [29]. Sul and Korban [30] observed that adventitious shoot buds were firstly initiated along the basal end of cotyledons of P. sylvestris, and then proceed towards the apical end. A similar observation was noted here with cotyledons of $B$. snegalensis. It is likely that this is the site of active endogenous cytokinin synthesis inducing cell division and differentiation, thus resulting in a higher level of organogenesis than along other areas of the cotyledon. Apical meristematic cells in the embryo are a site for hormone synthesis and occasionally exhibit different needs of plant growth regulators for regeneration in comparison to other tissues [15]. Meristematic cells in $B$. senegalensis produced shoots through adventitious buds formation while at hypocotyle-root axis buds formed through direct organogenic (Figure 2(a)).

Presence of many types of responses were observed on explant, especially embryo, and have been reported. Ebrahimie et al. [24] reported both direct shoot organogenesis and somatic embryogenesis on the embryo explants of Cuminum cyminum. Direct shoot organogenesis occurred on the meristematic zone, while direct somatic embryogenesis was observed on the hypocotyl part of the embryo. An important advantage of direct organogenesis is potential for maintaining genomic stability of regenerated plants, whereas regeneration via an intermediate callus phase increases the possibility of somaclonal variations [31]. 


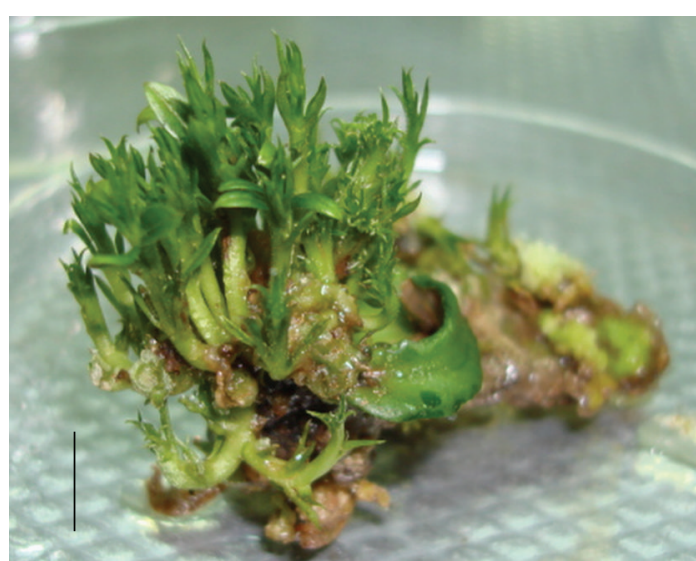

(a)

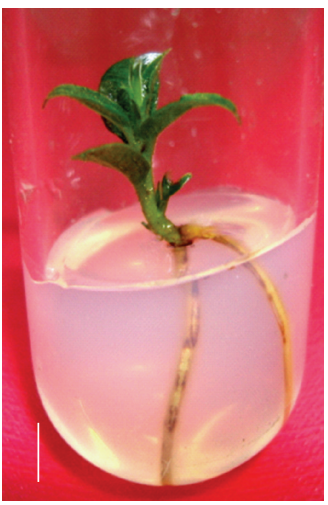

(b)

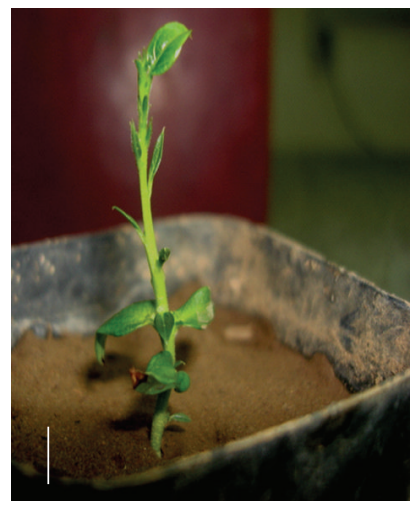

(c)

Figure 2: Plantlets forming from B. senegalensis mature green embryo. (a) Adventitious shoots induction on embryo in MS + BA 3 mg/L medium after 4 weeks of culture, Bar $=0.30 \mathrm{~cm}$. (b) In vitro rooting of shoots in $1 / 2 \mathrm{MS}+\mathrm{IBA}$ media, Bar $=0.75 \mathrm{~cm}$. (d) An acclimatized plant under greenhouse conditions, $\mathrm{Bar}=0.35 \mathrm{~cm}$.

3.3. In Vitro Rooting of Microshoots. For any micropropagation protocol, successful rooting of microshoots is a prerequisite to facilitate their establishment in soil. Rooting occurred sporadically when shoots were transfered to hormone-free medium or to media containing IBA (Table 2). Irrespective of media compositions, root initiation was observed after 1-2 weeks from the transfer. Using this procedure, $67 \%$ of shoots were successfully rooted after four weeks of culturing. The occurrence of root formation on auxin-free medium may be due to the availability of endogenous auxin in in vitro shoots. Among all the treatments tried, maximum number of roots and root length per responsive explant was observed on medium containing $0.25 \mathrm{mg} / \mathrm{L}$ IBA (Table 2; Figure 2(c)). IBA concentration higher than optimal led to a decrease in the number of roots and root length per rooted explant and rooting rate. The root elongation phase is very sensitive to auxin concentration, and it is inhibited by high concentration of auxin in the rooting medium [32]. Taiz and Zeiger [33] (2002) reported that roots may require a less concentration of auxin to grow, but root growth is strongly inhibited by its higher level because at this level, auxin induces the production of ethylene, a root growth inhibitor. Moreover, Baker and Wetzstein [32] reported that higher concentration of auxin induces the higher level of degradative metabolites in tissues thus blocking the regeneration process. However, IBA has been shown to be very effective in root induction in various species of tropical trees such as Psidium guajava [26], Balanites aegyptiaca [27], Azadirachta indica [34], and Albizia odoratissima [35]. Nevertheless, after two subcultures (every 4 weeks), when microshoots were harvested for in vitro rooting, a decline in rhizogenesis ability was observed (data not shown). The carry-over effect from cytokinins in the shoot proliferation medium, especially when using a cytokinin as persuasive as $\mathrm{BA}$, as is well known, may influence in vitro rooting of excised microshoots [36].

The in vitro-germinated plants were acclimatized in soil under shady conditions with a survival rate of $70 \%$
(Figure 2(c)). These plants were phenotypically normal, healthy, and similar to donor plants. This protocol will be useful for overcoming seed germination inconveniences and for rapid multiplication and conservation of $B$. senegalensis using zygotic embryo culture.

\section{Conclusions}

Embryo culture has become a well-recognized and widely used method to obtain plants from wide crosses whose seeds generally abort due to failure of germination. In vitro culture of Boscia will be beneficial for efficient genetic conservation by organ culture, useful secondary materials production by cell culture and basic cellular level research for the elucidation of its unique biological character. Microplant propagation through multiple and organogenic shoot formation is directly induced from B. senegalensis embryo without an intervening callus. This drastically reduces the duration of shoot regeneration in vitro.

\section{Abbreviations \\ BA: 6-Benzyl adenine \\ 2, 4-D: 2, 4-Dichlorophenoxyacetic acid \\ IBA: Indole-3-butyric acid \\ NAA: $\quad \alpha$-Naphthalene acetic acid \\ MS: Murashige and Skoog \\ PGR: Plant growth regulator \\ TDZ: Thidiazuron.}

\section{Acknowledgments}

The authors acknowledge all the colleagues in their lab for the constructive discussion and technical support. In addition, they are also grateful to all the staff of Desertification Research Institute (DRI), Al-Rawakeeb Research Station, for providing experiment materials. 


\section{References}

[1] D. Seck, G. Lognay, E. Haubruge, M. Marlier, and C. Gaspar, "Alternative protection of cowpea seeds against Callosobruchus maculatus (F.) (Coleoptera: Bruchidae) using hermetic storage alone or in combination with Boscia senegalensis (Pers.) Lam ex Poir," Journal of Stored Products Research, vol. 32, no. 1, pp. 39-44, 1996.

[2] National Research Council, Lost Crops of Africa, Volume III: Fruits, The National Academies Press, Washington, DC, USA, 2008.

[3] O. M. Salih, A. M. Nour, and D. B. Harper, "Chemical and nutritional composition of two famine food sources used in Sudan, mukheit (Boscia senegalensis) and maikah (Dobera roxburghi)," Journal of the Science of Food \& Agriculture, vol. 57, no. 3, pp. 367-377, 1991.

[4] M. H. Dicko, R. Hilhorst, and A. S. Traore, "Indigenous West African plants as novel sources of polysaccharide degrading enzymes: application in the reduction of the viscosity of cereal porridges," African Journal of Biotechnology, vol. 4, no. 10, pp. 1095-1104, 2005.

[5] T. R. Kim, A. Pastuszyn, D. J. Vanderjagt, R. S. Glew, M. Millson, and R. H. Glew, "The nutritional composition of seeds from Boscia senegalensis (Dilo) from the Republic of Niger," Journal of Food Composition and Analysis, vol. 10, no. 1, pp. 73-81, 1997.

[6] A. de Waal, Famine that Kills, Darfur, Sudan, 1984-85, Clarendon Press, Oxford, UK, 1989.

[7] G. Lognay, D. Seck, M. Maklier, E. Haubruge, C. Gaspar, and M. Severin, "Identification of elemental sulphur (S8) in Boscia senegalensis (PERS.) LAM ex POIR. leaves," Bulletin des Recherches Agronomiques de Gembloux, vol. 28, no. 4, pp. 501505, 1993.

[8] S. Antoine, S. Sibiri, D. Clementine, O. A. Patoin, and H. Jacques, "Combining Boscia senegalensis Lamarck (Capparaceae) leaves and augmentation of the larval parasitoid Dinarmus basalis Rondani (Hymenoptera: Pteromalidae) for Bruchid control in stored Cowpeas," Journal of Entomology, vol. 2, no. 1, pp. 40-45, 2005.

[9] A. Rinaudo, P. Patel, and L. A. J. Thomson, "Potential of Australian Acacias in combating hunger in semi-arid lands," Conservation Science Western Australia, vol. 4, no. 3, pp. 161169, 2002.

[10] Y. Yu, J. M. Baskin, C. C. Baskin, Y. Tang, and M. Cao, "Ecology of seed germination of eight non-pioneer tree species from a tropical seasonal rain forest in southwest China," Plant Ecology, vol. 197, no. 1, pp. 1-16, 2008.

[11] P. Berjak and N. W. Pammenter, "Recalcitrant seeds," in Handbook of Seed Physiology: Applications to Agriculture, R. L. Benech-Arnold and R. A. Sanchez, Eds., chapter 10, Food Products Press and the Haworth Reference Press, Imprints of the Haworth Press, 2004.

[12] H. W. Pritchard, M. I. Daws, B. J. Fletcher, C. S. Gaméné, H. P. Msanga, and W. Omondi, "Ecological correlates of seed desiccation tolerance in tropical African dryland trees," American Journal of Botany, vol. 91, no. 6, pp. 863-870, 2004.

[13] S. J. Milton and W. R. J. Dean, "How useful is the keystone species concept, and can it be applied to Acacia erioloba in the Kalahari Desert?" Zeitschrift fur Okologie und Naturschutz, vol. 4, no. 3, pp. 147-156, 1995.

[14] H. Mercier, B. M. Souza, J. E. Kraus, R. M. Hamasaki, and B. Sotta, "Endogenous auxin and cytokinin contents associated with shoot formation in leaves of pineapple cultured in vitro," Brasilian Journal of Plant Physiology, vol. 15, no. 2, pp. 107112, 2003.

[15] S. Shimizu-Sato, M. Tanaka, and H. Mori, "Auxin-cytokinin interactions in the control of shoot branching," Plant Molecular Biology, vol. 69, no. 4, pp. 429-435, 2009.

[16] V. M. Kapchina-Toteva, E. T. Iakimova, and I. P. Chavdarov, "Effect of cytokinins on in vitro cultured Exacum affine Balf," in Proceedings of the Balkan Scientific Conference of Biology, B. Gruev, M. Nikolova, and A. Donev, Eds., pp. 714-722, Plovdiv, Bulgaria, May 2005.

[17] U. J. Mehta, S. M. Barreto, and S. Hazra, "Effect of thidiazuron in germinating tamarind seedlings," In Vitro Cellular and Developmental Biology-Plant, vol. 40, no. 3, pp. 279-283, 2004.

[18] C. D’Onofrio and S. Morini, “Development of adventitious shoots from in vitro grown Cydonia oblonga leaves as influenced by different cytokinins and treatment duration," Biologia Plantarum, vol. 49, no. 1, pp. 17-21, 2005.

[19] C. A. Huetteman and J. E. Preece, "Thidiazuron: a potent cytokinin for woody plant tissue culture," Plant Cell, Tissue and Organ Culture, vol. 33, no. 2, pp. 105-119, 1993.

[20] X. Zhang and E. H. Ervin, "Cytokinin-containing seaweed and humic acid extracts associated with creeping bentgrass leaf cytokinins and drought resistance," Crop Science, vol. 44, no. 5, pp. 1737-1745, 2004.

[21] I. Yordanov, V. Velikova, and T. Tsonev, "Plant responses to drought, acclimation, and stress tolerance," Photosynthetica, vol. 38, no. 2, pp. 171-186, 2000.

[22] F. T. M. Kors, Duchefa Catalogue-Biochemicals Plant Cell and Tissue Culture, Duchefa Biochemie, Haarlem, The Netherlands, 2003.

[23] J. Pospíilová, H. Synková, and J. Rulcová, "Cytokinins and water stress," Biologia Plantarum, vol. 43, no. 3, pp. 321-328, 2000 .

[24] E. Ebrahimie, M. R. Naghavi, A. Hosseinzadeh et al., "Induction and comparison of different in vitro morphogenesis pathways using embryo of cumin (Cuminum cyminum L.) as a model material," Plant Cell, Tissue and Organ Culture, vol. 90, no. 3, pp. 293-311, 2007.

[25] N. A. Saeed, Y. Zafar, and K. A. Malik, "A simple procedure of Gossypium meristem shoot tip culture," Plant Cell, Tissue and Organ Culture, vol. 51, no. 3, pp. 201-207, 1997.

[26] M. K. Rai, V. S. Jaiswal, and U. Jaiswal, "Shoot multiplication and plant regeneration of guava (Psidium guajava L.) from nodal explants of in vitro raised plantlets," Journal of Fruit and Ornamental Plant Research, vol. 17, no. 1, pp. 29-38, 2009.

[27] I. Siddique and M. Anis, "Direct plant regeneration from nodal explants of Balanites aegyptiaca L. (Del.): a valuable medicinal tree," New Forests, vol. 37, no. 1, pp. 53-62, 2009.

[28] J. N. Buah, E. Danso, K. J. Taah et al., "The effects of different concentrations cytokinins on the in vitro multiplication of plantain (Musa sp.)," Biotechnology, vol. 9, no. 3, pp. 343-347, 2010.

[29] J. Medford, R. Horgan, Z. El-Sawi, and H. J. Klee, "Alterations of endogenous cytokinins in transgenic plants using a Chimeric lsopentenyl Transferase gene," Plant Cell, vol. 1, pp. 403-413, 1989.

[30] I. I. I. W. Sul and S. S. Korban, "Effects of salt formulations, carbon sources, cytokinins, and auxin on shoot organogenesis from cotyledons of Pinus pinea L," Plant Growth Regulation, vol. 43, no. 3, pp. 197-205, 2004. 
[31] W. Tang and Z. Guo, "In vitro propagation of loblolly pine via direct somatic organogenesis from mature cotyledons and hypocotyls," Plant Growth Regulation, vol. 33, no. 1, pp. 25-31, 2001.

[32] C. M. Baker and H. Y. Wetzstein, "Influence of auxin type and concentration on peanut somatic embryogenesis," Plant Cell, Tissue and Organ Culture, vol. 36, no. 3, pp. 361-368, 1994.

[33] L. Taiz and E. Zeiger, Mineral Nutrition: Plant Physiology, Sinaver Associates, 2nd edition, 2002.

[34] R. Chaturvedi, M. K. Razdan, and S. S. Bhojwani, "In vitro morphogenesis in zygotic embryo cultures of neem (Azadirachta indica A. Juss.)," Plant Cell Reports, vol. 22, no. 11, pp. 801-809, 2004.

[35] V. Rajeswari and K. Paliwal, "In vitro adventitious shoot organogenesis and plant regeneration from seedling explants of Albizia odoratissima L.f. (Benth.)," In Vitro Cellular and Developmental Biology_Plant, vol. 44, no. 2, pp. 78-83, 2008.

[36] D. V. Ružić and T. I. Vujović, "The effects of cytokinin types and their concentration on in vitro multiplication of sweet cherry cv. Lapins (Prunus avium L.)," Horticultural Science, vol. 35 , no. 1, pp. 12-21, 2008. 

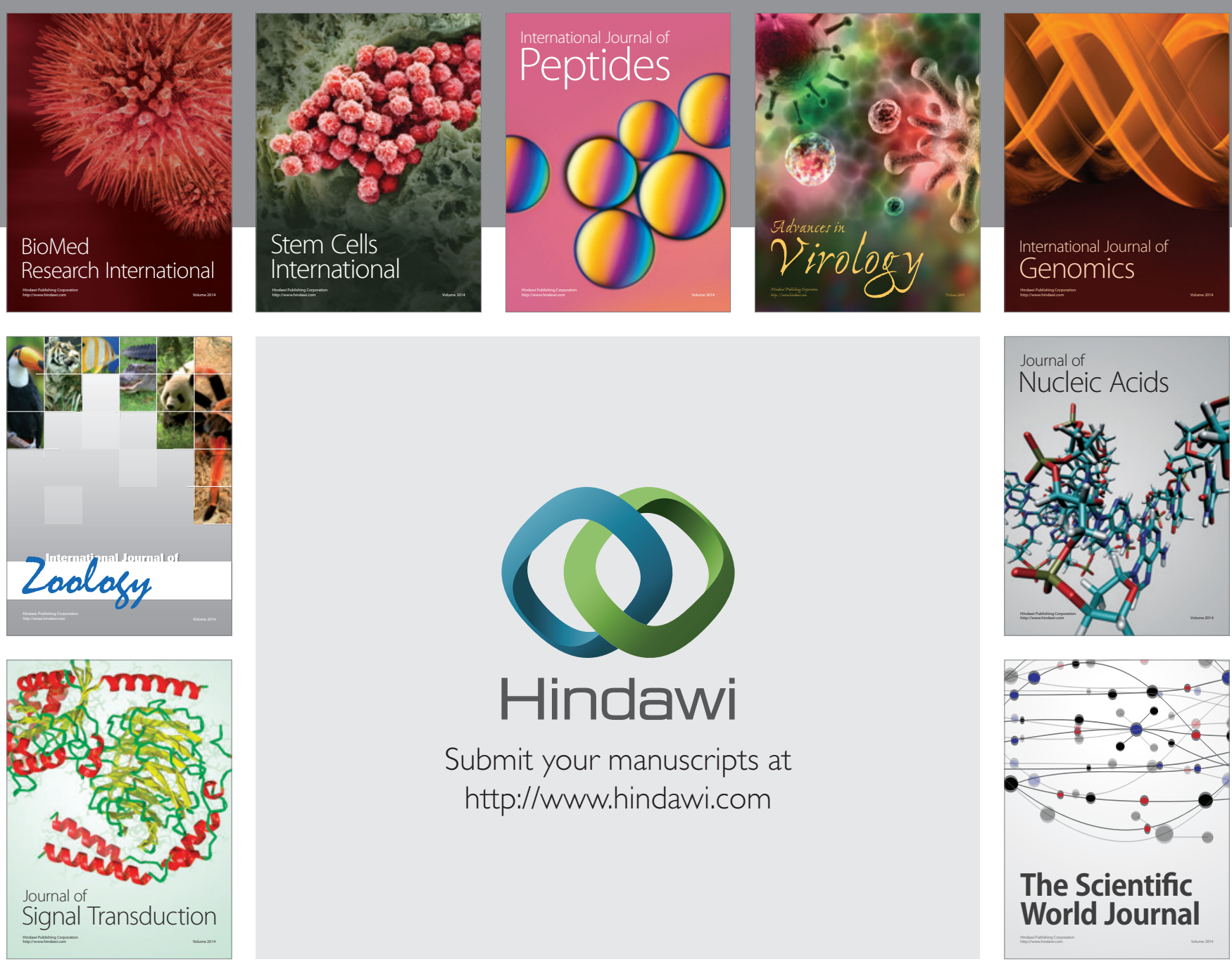

Submit your manuscripts at

http://www.hindawi.com
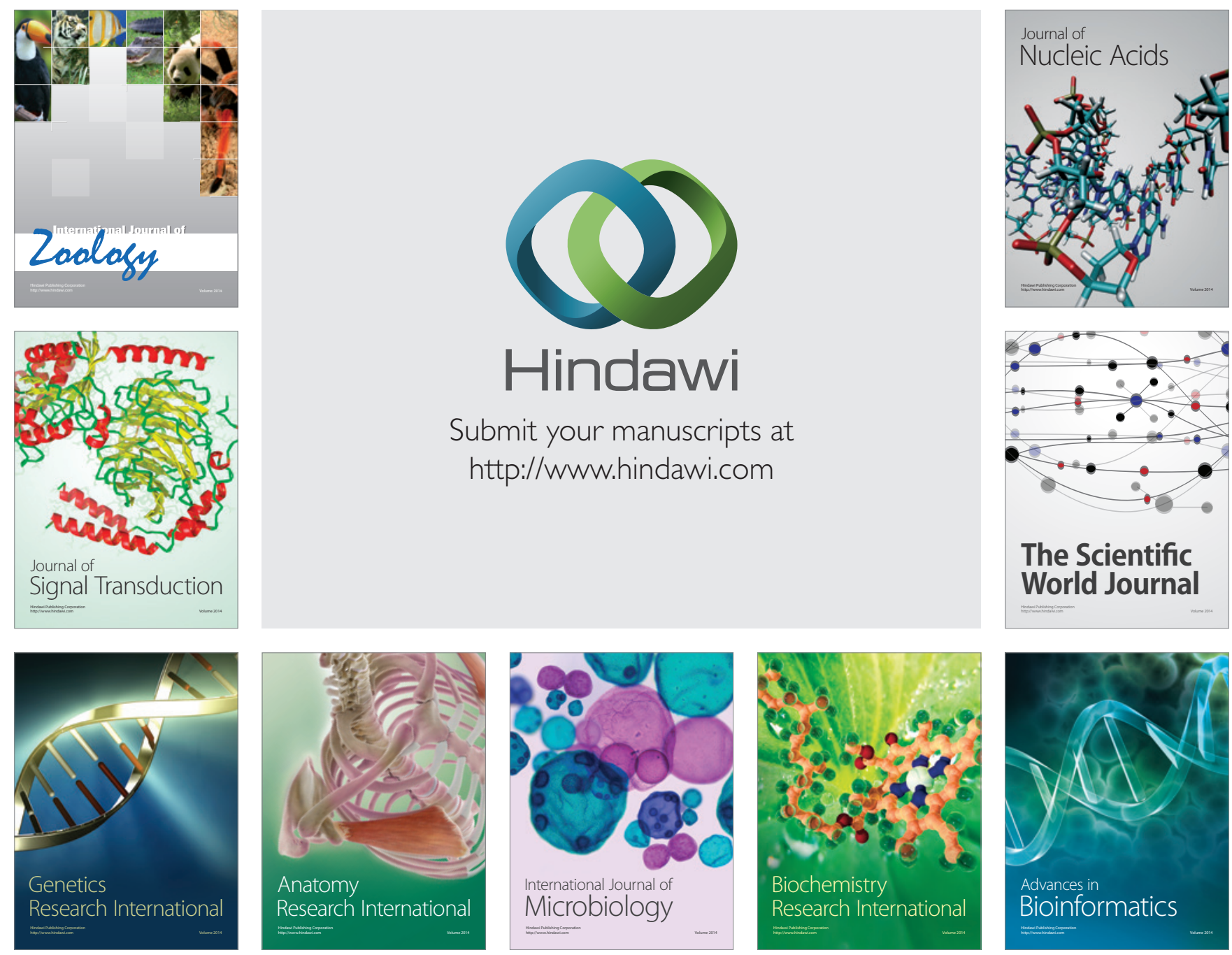

The Scientific World Journal
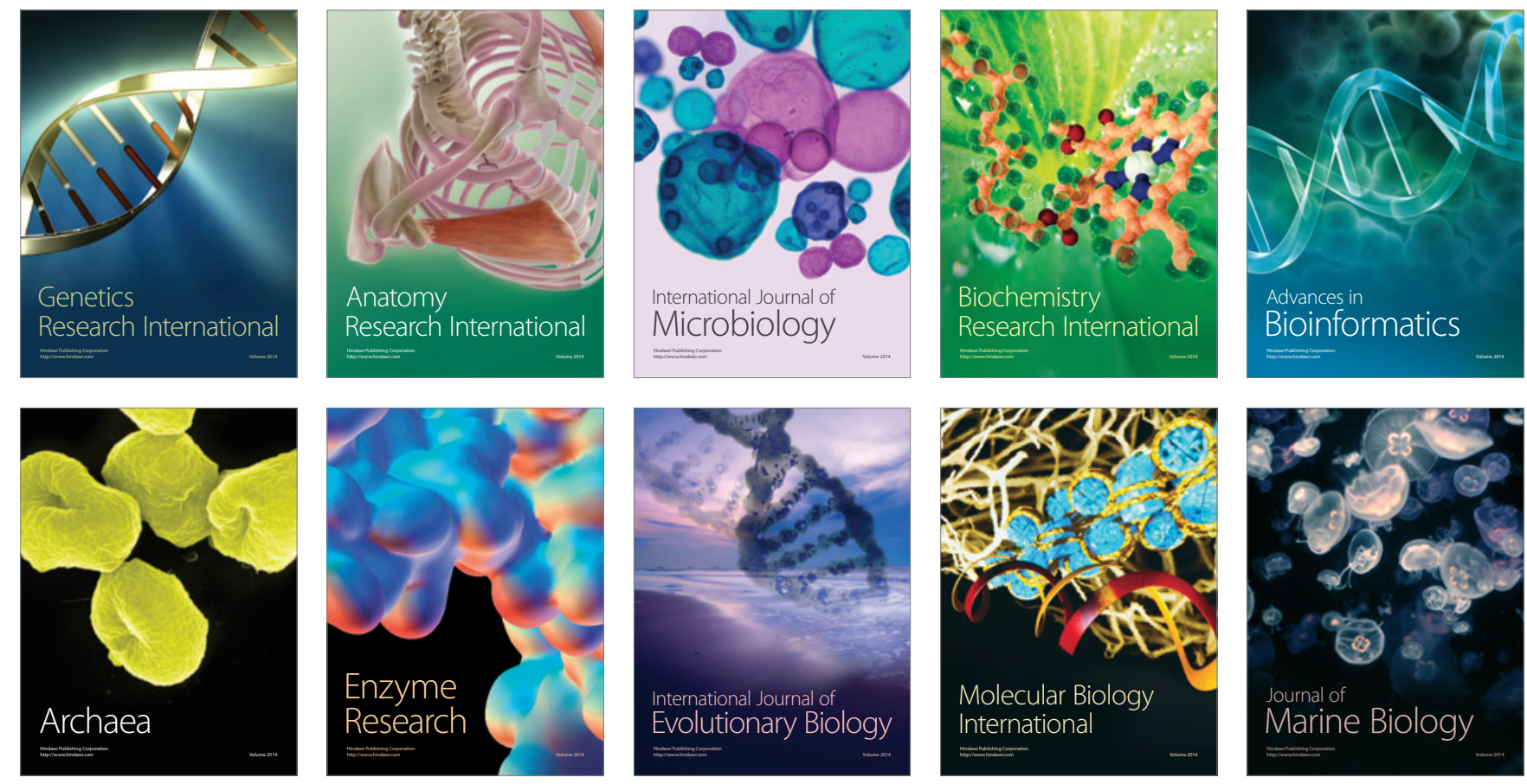